\title{
A CARTOGRAFIA COMPLEXA ENQUANTO MÉTODO DE PESQUISA NA LINGUÍSTICA APLICADA: ESBOÇANDO E AVALIANDO UM CONCEITO ${ }^{1}$
}

DOI: $10.48075 /$ ri.v24i1.25272

\begin{abstract}
Alan Ricardo Costa ${ }^{2}$
Nize Maria Campos Pellanda ${ }^{3}$

Vanessa Ribas Fialho ${ }^{4}$

RESUMO: Neste estudo, temos como objetivos a proposição e a avaliação da "cartografia complexa" enquanto método transdisciplinar pertinente ao campo da Linguística Aplicada (LA) e outras áreas afins. O referencial teórico do artigo abarca os pressupostos da Biologia da Cognição e do Paradigma da Complexidade. $O$ estudo caracteriza-se como uma pesquisa metodológica, cujo enfoque recai sobre o próprio fazer científico e o (re)pensar de procedimentos e métodos. Primeiramente, é feito uma revisão da literatura sobre o método cartográfico. Na sequência, apresentamos a experiência de implementação e avaliação de uma cartografia complexa tecida no âmbito de um curso online de formação docente realizado com 13 docentes graduadas ou graduandas em Letras na Educação a Distância (EaD). O contexto da pesquisa é esse curso online, realizado em 2019 , ao longo de quatro semanas, nas quais as docentes-cursistas escreveram autonarrativas, que são instrumentos potentes de uma epistemologia complexa. Concluímos que a cartografia complexa - enquanto método - pode contribuir com as pesquisas em LA no sentido de que ela pode dar conta de uma realidade dinâmica e da dimensão subjetiva dessa realidade.
\end{abstract}

Palavras-chave: Linguística Aplicada, Metodologia, Cartografia Complexa, Biologia da Cognição, Paradigma da Complexidade.

\footnotetext{
${ }^{1} \mathrm{O}$ presente artigo é oriundo da tese de Doutorado em Letras intitulada "Contribuições para uma cartografia complexa da ontoepistemogênese: autonarrativas e formação docente na Educação a Distância" (COSTA, 2021).

2 Doutorando do Programa de Pós-Graduação em Letras (PPGL) da Universidade de Santa Cruz do Sul (UNISC), com bolsa CAPES. Mestre em Linguística Aplicada pela Universidade Católica de Pelotas (UCPel). E-mail: alan.dan.ricardo@gmail.com.

${ }^{3}$ Doutora em Educação pela Universidade Federal do Rio Grande do Sul (UFRGS), Mestra em História pela Pontifícia Universidade Católica do Rio Grande do Sul (PUCRS). Atualmente integra o quadro de docentes do Programa de Pós-Graduação em "Cognição, Tecnologias e Instituições" da Universidade Federal Rural do SemiÁrido (UFERSA). E-mail: nizepe@gmail.com.

${ }^{4}$ Doutora em Letras e Mestra em Linguística Aplicada pela Universidade Católica de Pelotas (UCPel). Professora Associada do Departamento de Letras Estrangeiras Modernas (DLEM) da Universidade Federal de Santa Maria (UFSM). E-mail: vanessafialho@gmail.com.
} 


\title{
COMPLEX CARTOGRAPHY AS RESEARCH METHOD IN APPLIED LINGUISTICS: OUTLINING AND EVALUATING A CONCEPT
}

\begin{abstract}
ABSTRAC: In this study, the objective is the proposition and evaluation of "complex cartography" as a transdisciplinary method relevant to the field of Applied Linguistics (AL) and other correlated areas. The theoretical background of the article covers the assumptions of Biology of Cognition and the Paradigm of Complexity. The study is characterized by a methodological research, whose focus relies on its own scientific approach and the (re)thinking of procedures and methods. Firstly, a literature review on the cartographic method is done. After that, we presented an experience of implementation and evaluation of a complex cartography in an online teacher training course, carried out with 13 teachers who were graduated or undergraduate students of Modern Language Distance Learning. The context of the research is this online course, carried out in 2019, during four weeks, in which the teachers-course takers wrote self-narratives, which are powerful tools of a complex epistemology. It was possible to conclude that complex cartography - as a method - may contribute to the research in AL in the sense that it may embrace a dynamic reality and of the subjective dimension of that reality.
\end{abstract}

Key Words: Applied Linguistics, Methodology, Complex Cartography, Biology of Cognition, Paradigm of Complexity.

\section{INTRODUÇÃO}

A noção de uma Linguística Aplicada (LA) limitada a mero campo de aplicação de teorias da Linguística é inadequada, reducionista e ultrapassada. Enquanto seara indisciplinar, mestiça, híbrida e transgressiva (MOITA-LOPES, 2006), que se ocupa de múltiplas questões de linguagens, a LA contemporânea pode servir-se de perspectivas teórico-metodológicas de diversas áreas (a Psicologia, a Filosofia, a Sociologia, a Cibernética, a Pedagogia...), assim como pode gerar sua própria teorização para as questões levantadas pelos pesquisadores (COSTA et al., 2020).

Nesse viés, temos na atualidade uma LA crítica (MOITA-LOPES, 2006), não apenas no sentido de expansão de seus horizontes (ARAGÃO, 2005) e de suas reflexões epistemológicas para formas mais complexas de conceber o fazer científico, mas também enquanto área que se autoavalia e reflete sobre sua agenda de pesquisa. Com o presente trabalho, buscamos dar conta desses dois aspectos importantes para a LA brasileira: por um lado, propomos um alargamento dos horizontes da LA no que tange à concepção de "cartografia" e sua contribuição à área; por outro lado, tentamos colaborar com o 
preenchimento de uma lacuna na agenda de pesquisa nacional, sinalizada em Costa et al. (2020), a saber: a importância de fomento e difusão de pesquisas metodológicas ${ }^{5}$.

Segundo Paiva (2019), no que concerne ao gênero, as pesquisas podem ser classificadas como "teóricas", "metodológicas", "práticas" ou "empíricas".

A pesquisa teórica se propõe a estudar teorias, construir ou modificar uma teoria ou ainda contribuir com novos conceitos. A pesquisa metodológica é o estudo de métodos e procedimentos de pesquisa. A pesquisa prática se caracteriza por intervir no contexto pesquisado se apoiando em conhecimentos científicos, e a empírica se baseia na observação e em experiências de vida (PAIVA, 2019, p. 11).

Haja vista o crescente interesse pelos pressupostos do Pensamento Complexo (MORIN, 1977) e da Biologia da Cognição (MATURANA; VARELA, 2001) na LA ${ }^{6}$, neste estudo, lançamos mão do referido arcabouço teórico para contribuir com a área, a partir da proposição e da avaliação de um conceito de "cartografia complexa". Propor o esboço desse conceito e avaliá-lo de forma prática são os objetivos do presente trabalho.

Organizamos o conteúdo deste artigo em cinco seções, sendo a primeira delas esta Introdução. Na segunda seção, tratamos do Paradigma da Complexidade e, subjacente a ele, de algumas ressignificações de conceitos, como os de "método" e "análises de dados" no fazer científico. Na sequência (terceira seção), apresentamos uma breve revisão da literatura sobre o método cartográfico, dando ênfase às perspectivas teóricas em sinergia com o Paradigma da Complexidade (MORIN, 1977). Na quarta seção, apresentamos o contexto da presente pesquisa, desenvolvida no âmbito de um curso online de formação docente realizado a partir de uma ação de extensão da Universidade de Santa Cruz do Sul (UNISC) em parceria com a Universidade Federal de Santa Maria (UFSM). Tal curso foi ofertado em 2019 a 13 professoras de línguas formadas ou em formação na modalidade Educação a Distância (EaD). Na quarta seção deste artigo, tecemos interpretações sobre a implementação e a avaliação inicial de uma cartografia complexa no referido contexto de formação docente,

\footnotetext{
${ }^{5}$ Em análise dos Cadernos de Resumos de um evento da área de Ensino de Línguas Mediado por Computador, realizado anualmente há uma década (com sua primeira edição em 2011), Costa et al. (2020) notaram alta incidência de pesquisas teóricas e práticas, mas baixa ocorrência de pesquisas metodológicas (apenas uma entre os 236 trabalhos analisados). Interpretando esse corpus como representativo da LA, e considerando o melhor do nosso conhecimento da literatura da área, corroboramos a opinião de que temos poucas pesquisas metodológicas.

${ }^{6}$ Os pressupostos epistemológicos da Complexidade e da Biologia da Cognição estão sendo adotados como arcabouço teórico de questões linguísticas em um número cada vez maior de pesquisas, conforme apontado em Costa et al. (2019). Ainda que não tenham sido originalmente pensados como suporte teórico para problemas da LA, os referidos pressupostos servem para tal fim, conforme vêm nos mostrando inúmeros autores (LARSEN-FREEMAN, 1997; ARAGÃO, 2005; COSTA et al., 2019; COSTA, 2020).
} 
destacando, a modo de ilustração, dois marcadores emergentes: o acoplamento tecnológico e o processo de autopoiesis, que serão apresentados ao longo do texto.

\section{DO PARADIGMA CLÁSSICO À COMPLEXIDADE}

Conforme registrado em Costa (2021), "metodologia de pesquisa", "análise de dados" e outros jargões acadêmicos - ainda hoje muito recorrentes no meio universitário podem ser empregados com sentidos e significações que aludem a um fazer científico inerente ao "Paradigma Clássico" (PELLANDA; BOETTCHER, 2017). Esse Paradigma Clássico, cartesiano e positivista, trouxe consequências deletérias à vida dos seres humanos em termos existenciais, cognitivos, ontológicos, éticos e sociais (PELLANDA; BOETTCHER; PINTO, 2017), devido à extrema fragmentação das dimensões da realidade (COSTA, 2021).

O Paradigma da Complexidade (MORIN, 1977) opõe-se ao Paradigma Clássico, no sentido de interpretar como insustentável uma lógica excessivamente positivista, por sua radicalidade, na medida em que pressupõe o apagamento do "sujeito autor" no fazer científico e, ao mesmo tempo, atrela-se à fragmentação (ou disciplinarização) dos saberes. Sobre essa questão, Gai (2009, p. 138) destaca: o paradigma científico clássico, no apogeu da Modernidade, centralizou-se na racionalidade e considerou a evidência física enquanto única premissa da verdade, o que, mais tarde, revelou-se um caminho insuficiente de acesso ao conhecimento (COSTA, 2021). Em outras palavras: a lógica subjacente a esse paradigma anterior (clássico) é uma lógica formal, linear, simplista e excludente, que teria causado as implicações referidas. Optamos, então, por lógicas complexas, não lineares, capazes de responder às incertezas, às flutuações e às dimensões sutis da realidade (COSTA, 2021).

Pela necessidade de um posicionamento teórico-metodológico em sinergia com o Pensamento Complexo, pesquisadores podem opor-se a esse paradigma clássico esgotado (PELLANDA; BOETTCHER, 2017) por meio de ressignificações e subversões de sentidos atrelados às palavras. Queremos dizer, com isso, que é possível demarcar uma oposição ao paradigma cientificista clássico evitando alguns termos considerados "malditos", pela sua limitação conceitual, bem como ressignificando outros tantos, mais capazes de vincular-se ao prisma da Complexidade (COSTA, 2021).

Essa prática de alargar determinadas acepções e, com isso, resgatá-las das amarras simplificadoras de epistemologias lineares e fragmentadoras da realidade, tem sido 
recorrente no Grupo de Ações e Investigações Autopoiéticas $\left(G A I A^{7}\right)$, do qual parte o presente estudo. O GAIA é um grupo de pesquisa vinculado ao eixo "Educação e Complexidade" e que tem como metas maiores estudar e praticar a educação numa perspectiva complexa, razão pela qual ressignificamos noções como "cognição" e "narrativa" (PELLANDA, 2008; PELLANDA; BOETTCHER; PINTO, 2017; COSTA, 2021).

Destarte, quando tomamos, por exemplo, a etapa da "análise de dados" de uma pesquisa, interpretamos que tal terminologia não estabelece sintonia adequada com o fazer científico do GAIA (COSTA, 2021). Em primeiro lugar, porque "nada está dado", se considerarmos o viés da Física Quântica, que questiona a própria natureza da matéria, "sustentando que a realidade fundamental é indeterminada, que nada está dado e que não existe nada determinado em relação à nossa vida cotidiana"8 (PELLANDA; BOETTCHER, 2017, p. 41). Afora isso, como observa Gai (2009, p. 139): “O ambiente, tal como o percebemos, é uma invenção nossa", assim como em qualquer narrativa (ficcional ou não) está implícita a ideia de invenção. Quer dizer:

a realidade é um conceito construído; é conformada a partir da explicação da experiência do observador implicado; este é um ser vivente, ou seja, é o ser que se observa a si mesmo sendo, o ser que se pensa a si mesmo no seu processo de viver, de existir (GAl, 2009, p. 139).

Consequentemente, em segundo lugar, entendemos que não "analisamos" algo, no sentido cartesiano da palavra, assumindo a pretensão de descrever o fenômeno, mas, sim, o interpretamos (COSTA, 2021). Entendemos que a "descrição" parece presumir noções de verdades e totalidades em fatos, o que pode ser questionado numa lógica complexa, diferentemente da noção de "interpretação", que não nega a correlação subjetivaçãocognição no processo de conhecer-viver. Partimos da popular ideia atribuída ao filósofo

\footnotetext{
${ }^{7}$ Grupo de pesquisa vinculado até pouco tempo atrás ao Programa de Pós-Graduação em Educação (PPGEdu) e ao Pós-Graduação em Letras (PPGL) da Universidade de Santa Cruz do Sul (UNISC). O GAIA é coordenado pela profa. Nize Maria Campos Pellanda que, enquanto docente da UNISC, foi orientadora da tese cuja pesquisa origina o presente artigo (COSTA, 2021). Posteriormente, com a mudança de Instituição de Ensino Superior da professora Nize, a tese passou a ser orientada pelo prof. Felipe Gustsack (UNISC). Mais informações sobre o GAIA em Pellanda, Boettcher e Pinto (2017), Costa e Piccinin (2020) e Costa (2021), ou no Diretório de Grupos de Pesquisa do CNPq, em: <http://dgp.cnpq.br/dgp/espelhogrupo/9220919329267993>.

${ }^{8}$ Há quem interprete que conceber a realidade a partir de uma noção de que "nada está dado" possa entrar em conflito com a noção de "caos determinístico". Sobre essa questão, elencamos três tópicos: (1) A acepção de "caos determinístico" deve ser considerada com cuidado, pois a natureza dita "determinista" dos sistemas complexos não os torna previsíveis, lineares ou menos dinâmicos; (2) Certas noções da física, como a de "determinismo", ao longo da história, vão mudando de acordo com os paradigmas científicos e as tendências teóricas de cada época e contexto, o que leva autores como Paty (2004) a questionar em quais sentidos alguns sistemas seriam realmente "deterministas"; (3) Justamente por questionarmos a polissemia subjacente à palavra "determinístico", e por coadunarmos da perspectiva de autores da área de LA mencionados ao longo deste artigo e que tratam de "caos", e não de "caos determinístico", não empregaremos tal expressão.
} 
Nietzsche - de que não há fatos, apenas interpretações (ver PIMENTA, 2020) -, não para incorrer na postura radical de negação dos fatos, mas para sinalizar nossa perspectiva teórica: o nosso ser-estar no mundo se dá por interpretações, por subjetivação-cognição (COSTA, 2021).

Nessa linha de pensamento, um dos termos que, no GAIA, buscamos ressignificar (de modo a retirar as conotações positivistas lançadas sobre ele) é o próprio "método" (COSTA, 2021). Almejamos, na linha de Passos e Barros (2012, p. 17), uma reversão do sentido de "método", quer dizer, não mais um caminho trilhado para alcançar metas prefixadas ("metáhódos"), mas o primado do caminhar que traça, no caminho, suas metas; essa reversão afirma, pois, um "hódos-metá".

Portanto, quando empregamos no GAIA o termo "método", aludimos a um percurso metodológico à luz da Complexidade, isto é, um fazer científico a partir do qual olhamos determinados fenômenos com as lentes teóricas do Pensamento Complexo. Sob o prisma da Complexidade, buscamos um fazer científico em que, no convívio e no diálogo com a incerteza, possamos olhar e interpretar o objeto no seu contexto, juntando o que foi disjuntando, compreendendo nesse processo as recursividades, o caos, as simbioses e as complementaridades (COSTA, 2021). Nesse método, o objeto é vislumbrado na relação parte-todo, a partir de um princípio hologramático, que opera na configuração do reconhecimento da unidade na diversidade e da diversidade na unidade (MORIN, 1977).

Assim como Edgar Morin, encontramos na origem da palavra "método" o significado de "caminho", mas apenas para aceitar o "caminhar sem caminho", que é também o "fazer o caminho no caminhar" (MORIN, 1977, p. 25). Citando o poeta espanhol Antonio Machado ("Caminante no hay camino, se hace camino al andar"), Morin (1977, p. 25) nos lembra que o método só pode formar-se durante a investigação.

Essa ideia de caminhar e fazer a pesquisa no caminho não é totalmente nova na LA, conforme registro de Leffa (2001), em um clássico texto sobre a área e seu compromisso social. Segundo o autor (LEFFA, 2001, p. 4), o grande desafio de fazer pesquisas em LA pode ser ilustrado pela metáfora da busca por petróleo no mar: para tanto, nós, pesquisadores, "precisamos abandonar o conforto de caminhar em terra firme, com balizas enterradas no chão, e aprender a navegar". Outra metáfora pertinente é a do papel do laboratório no fazer científico do pesquisador em LA: para Leffa (2001), na condição de cientistas, não trazemos

\footnotetext{
9 “Caminhante, não há caminho, o caminho se faz ao andar" (tradução nossa). 
um problema a ser estudado para dentro do laboratório, limpo e desinfetado, cuidadosamente desembaraçado de todas as variáveis que possam atrapalhar ou sujar nossas hipóteses. "Fazemos o caminho inverso. Saímos do laboratório e vamos pesquisar o problema onde ele estiver: na sala de aula, na empresa ou na rua" (LEFFA, 2001, p. 7). O pesquisador - que aqui estamos nomeando especificamente como cartógrafo - cartografa em vida, no fluxo do viver, em uma epistemologia complexa, da mesma forma que pesquisa trilhando o caminho do pesquisar.

Nesse mesmo sentido, vale debater: em pesquisas práticas, aplicadas ou experimentais, a interpretação e a discussão dos dados geralmente são feitas a partir de "critérios de análise", delimitados previamente com base na literatura da área e/ou selecionados em função de padrões estabelecidos a priori. Para a presente pesquisa, contudo, tal procedimento metodológico não é adotado, em função da perspectiva complexa subjacente ao estudo. Conforme elucida Pellanda (2008), no GAIA,

Não trabalhamos com categorias porque acreditamos que elas não são adequadas para lidar com uma realidade complexa e sempre em devir. As categorias essencializam os fenômenos e isso compromete o tipo de abordagem que estamos querendo atingir (PELLANDA, 2008, p. 1080).

A análise (ou melhor, a interpretação) e a discussão dos fenômenos vividos são feitas a partir de emergências que afetaram e perturbaram os pesquisadores, e que possivelmente tenham perturbado também os docentes participantes do curso de formação proposto e implementado. O ponto de partida para a pesquisa é uma disciplina do PPGEdu da UNISC voltada para a proposição de espaços formativos para professores, na qual foi concebido um curso totalmente online de formação e capacitação docente sobre tecnologias digitais. Em tal curso, os participantes foram provocados a produzir autonarrativas (COSTA, 2021). A considerar que os indivíduos narram pela necessidade de dar sentido ao vivido, aquilo que é registrado por um docente em sua autonarrativa pode ser entendido como uma emergência suficientemente significativa.

Essas emergências registradas em autonarrativas e estudadas à luz do Paradigma da Complexidade e da Biologia da Cognição (MATURANA, 1997), considerando "padrões de organização individual e/ou comunitários" (OLIVEIRA, 2017), permitem a cartografia complexa, que é uma das alternativas daquilo que, no GAIA, inspirados no biólogo chileno Francisco Varela, chamamos de "metodologia de primeira pessoa" (PELLANDA; BOETTCHER, 2017, p. 67). Essa metodologia de primeira pessoa é, em síntese, uma perspectiva 
metodológica que entende que: (1) conhecer é um ato sobre mim mesmo; (2) não existe representação ou dados; e (3) nós nos constituímos nos narrando e nos entendemos como humanos - nos nossos modos de ser - por meio de tecnologias autopoiéticas, como as próprias autonarrativas (COSTA, 2021).

\section{CARTOGRAFIA COMPLEXA: ESBOÇANDO UM CONCEITO}

A tese de Doutorado em Letras que origina o presente artigo (COSTA, 2021) tem como método central a "cartografia complexa", vislumbrada sob um prisma qualitativo e transdisciplinar. Interpretamos essa cartografia complexa como uma possibilidade de acompanhar e viver, em fluxo, os processos da investigação (PELLANDA; BOETTCHER, 2017; CHAGAS, 2019).

Limberger et al. (2017, p. 194) elucidam que a cartografia, enquanto ciência, "volta seus estudos para a construção e a compreensão de mapas, com a finalidade de orientar as pessoas no que se refere a sua localização". Entretanto, essa localização não pertence somente ao plano do aqui e agora, no qual o observador procura localizar-se exatamente onde se encontra (COSTA, 2021). A abordagem da cartografia também amplia o olhar para a visualização do caminho percorrido, ou mesmo para as possibilidades de planejar por onde se deseja locomover, traçando novos percursos (LIMBERGER et al., 2017).

Como método, a cartografia pode ser desenvolvida no viés dos estudos topográficos ou topológicos. Os estudos do primeiro tipo "buscam delinear o relevo de uma região para a confecção de mapas fixos e permanentes", enquanto os do segundo tipo "levam em consideração as constantes transformações do relevo, produzidas pela interação do homem com a natureza, abrangendo assim seus aspectos mutatórios" (LIMBERGER et al., 2017, p. 194). Desse modo, no GAIA, entendemos que cartografar-pesquisar à luz dos pressupostos da Complexidade

é deparar-se com elementos de cunho topológico, visto que não existem caminhos prontos; os mesmos devem ser construídos no decorrer da pesquisa, a cada passada. $\mathrm{O}$ ato de cartografar pertence ao presente, se refere a um processo que está acontecendo, uma ação que está sendo desenvolvida para conhecer uma realidade (LIMBERGER et al., 2017, p. 194).

Para Chagas (2019), a inserção da cartografia do tipo topológica nas pesquisas das ciências sociais tem sido ampliada e popularizada nos últimos anos. Autores como Rolnik 
(1989; 1997); Guattari e Rolnik (1996), Deleuze (2001), Escóssia e Tedesco (2009); Pellanda et al. (2017), Limberger et al. (2017), Chagas (2019), dentre outros, são alguns que desenvolveram e/ou desenvolvem trabalhos importantes de investigação cartográfica, abordando a subjetividade no fazer do conhecimento e, por conseguinte, contribuindo para a construção constante de uma noção de cartografia complexa enquanto método de pesquisa científica (COSTA, 2021).

Ainda segundo Chagas (2019), essas pesquisas qualitativas nas ciências sociais e humanas que utilizam a cartografia como método, em sua maioria, fundamentam-se nos pressupostos apresentados por Guattari e Rolnik (1996) e Deleuze e Guattari (1995). Estes abordam a potência da pesquisa em fluxo e a possibilidade de acompanhar os processos investigativos e a produção de subjetividades, contando com ações, em aberto, da cartografia. Na obra Mil platôs (1995), Deleuze e Guattari associam a cartografia ao conceito de rizoma para apresentar a produção de subjetividades como devir (CHAGAS, 2019). Nessa linha de pensamento, com base em Chagas (2019), cabe interpretar: sendo tarefa do cartógrafo dar língua para afetos que pedem passagem, dele se espera basicamente que esteja mergulhado nas intensidades de seu tempo e que, atento "às linguagens que encontra, devore as que the parecem elementos possíveis para a composição das cartografias que se fazem necessárias" (ROLNIK, 1989, p. 16).

No contexto do GAIA, com o respaldo da revisão da literatura da área (ROLNIK, 1989; 1997; DELEUZE, 2001; GUSTSACK; PELLANDA; BOETTCHER, 2017; CHAGAS, 2019), temos inventariado pressupostos teóricos para um esboço mais profundo de uma cartografia complexa (COSTA, 2021). Até o presente momento, pesquisas prévias nos permitem destacar como elementos componentes da cartografia complexa:

(1) O observador incluído. O cartógrafo, nesse sentido, está incluído em uma prática que convoca o olhar como uma modalidade em potencial (CHAGAS, 2019), isto é, aquela que ativa a capacidade de vibrar, ou ainda, que faz com que o olho seja tocado pela força do que vê (ROLNIK, 1997). Sobre isso, Pellanda et al. (2017, p. 132) escrevem que "o mundo físico mostra-se num movimento sem ordem, aleatório, que não faz nenhum sentido para um observador externo"; todavia, segundo os autores, "uma vez incluído esse observador, emerge o sentido a partir da ação efetiva na ordem viva, posicionando-se como alguém que inventa o mundo e não o contempla de fora simplesmente" (PELLANDA et al., 2017, p. 132). 
Considerando o observador incluído ${ }^{10}$, a cartografia complexa ajuda a compor essa experiência de investigação em uma "dimensão processual, ou seja, do plano coletivo das forças moventes" (ESCÓSSIA; TEDESCO, 2009, p. 99).

(2) O processo em sintonia com o próprio processo. Kastrup e Barros (2009, p. 77) destacam a cartografia como "um método processual, criado em sintonia com o domínio igualmente processual que ele abarca". Nesse viés, o método não fornece um modelo de investigação; a investigação se faz "através de pistas, estratégias e procedimentos concretos" (KASTRUP; BARROS, 2009, p. 77).

(3) As narrativas. Para Gonçalves (1998, p. 21), “a narrativa não é algo que escolhemos fazer, mas algo que somos, e, como o ser não é dissociável do conhecer, a narrativa é também aquilo que conhecemos". O autor afirma ainda que "tal como a vida, a narrativa é inerentemente aberta e multipotencial, abrindo-nos para uma multirrealidade e multirracionalidade" (GONÇALVES 1998, p. 21). Nesse sentido, a narrativa, que é fundamentalmente uma autonarrativa, compõe a cartografia complexa, em qualquer que seja o formato, a modalidade ou a técnica: falas, escritas, gestos, emoções, imagens, poesias, vídeos, diário de bordo, rodas de conversas etc.

(4) Os marcadores. Pellanda et al. (2017, p. 142) elucidam que marcador é tudo aquilo que serve "para sinalizar transformações nos sujeitos no devir dos processos vividos" e, com isso, possibilitar também a identificação de "padrões de sentido". Os marcadores, então, não são (e se opõem às) "categorias", que engessam uma realidade em devir. Até o presente momento, no GAIA, entre outros, temos usado como marcadores o processo autopoiético e o acoplamento tecnológico (PELLANDA et al., 2017, p. 142), que serão abordados nas próximas seções deste artigo.

Ademais de apontar aquilo que, por enquanto, entendemos como componentes de uma cartografia complexa, fazemos também o movimento inverso, isto é, destacar aquilo que, em nosso entendimento, não é próprio de tal método:

(1) A verdade. Com base em Chagas (2019), a cartografia complexa é um modo de pesquisar que não está vinculado à busca de verdades, pois "a verdade" significaria uma correspondência precisa entre a nossa descrição e aquilo que descrevemos, uma compreensão absoluta do mundo exterior, de acordo com Bateson e Bateson (2000). A verdade, tomada nesse sentido, não é atingível, segundo tais autores, pois nunca seremos

\footnotetext{
${ }^{10}$ Esta é uma prerrogativa relativamente antiga do pesquisar no Paradigma da Complexidade: o olhar do pesquisador como um dos elementos do sistema que observa (COSTA, 2021).
} 
capazes de reivindicar um conhecimento final, seja do que for (BATESON; BATESON, 2000). Partindo dessa premissa, no GAIA, nos afastamos da perspectiva cartesianarepresentacionista, para produzirmos um percurso sem verdades absolutas e certezas prontas (CHAGAS, 2019).

(2) O início e/ou o fim. Para Barros e Kastrup (2009, p. 59), quando se inicia "uma pesquisa cujo objetivo é a investigação de processos de produção de subjetividade, já há, na maioria das vezes, um processo em curso". Ainda segundo os autores, as ações do pesquisador-cartógrafo nesse percurso se encontram sempre na situação paradoxal de começar pelo meio, entre pulsações (CHAGAS, 2019). "Isso acontece não apenas porque o momento presente carrega uma história anterior, mas também porque o próprio território presente é portador de uma espessura processual" (BARROS; KASTRUP, 2009, p. 59). Portanto, temos entendido que essa cartografia tem uma característica genética, no sentido de busca dinâmica da gênese constante, isto é, acompanhando a realidade se fazendo em ato (COSTA, 2021).

A partir do que foi apresentado nesta breve revisão de literatura, concordamos com Chagas (2019): para uma experiência de investigação nos pressupostos da Complexidade (MORIN, 1977), acompanhando processos de complexificação ontoepistemogênica dos sujeitos em ato, a cartografia complexa é a uma ótima escolha para o estudo daquilo que emerge da experiência de um curso de formação docente (COSTA, 2021).

\section{CARTOGRAFIA COMPLEXA EM UM CURSO DE FORMAÇÃO DOCENTE}

Para dar conta da avaliação aplicada de uma cartografia complexa, foi idealizado e implementado um projeto de extensão da UNISC, em parceria com a UFSM, na forma de curso online (COSTA, 2021). Em tal curso, que serviu como espaço para o diálogo, a escuta sensível, o compartilhamento de vivências e a tecitura de reflexões sobre o percurso formativo das docentes-participantes, foi desenvolvida a cartografia complexa da ontoepistemogênese (PELLANDA et al., 2017). Como Ambiente Virtual de Aprendizagem (AVA) do curso, usamos um grupo no site de rede social Facebook. 
Foram selecionadas como participantes do curso (e, por conseguinte, deste estudo) 13 docentes, professoras-cursistas ${ }^{11}$ graduandas ou já graduadas pelo curso de licenciatura em Letras Espanhol e Literatura EaD da UFSM-UAB. O curso online, enquanto projeto de extensão de formação continuada, foi pensado e implementando considerando o contexto do referido curso de graduação EaD.

O curso de capacitação online foi realizado no final do ano de 2019, com duração de 4 semanas (totalizando 20 horas de atividades). Cada uma dessas semanas abordou a seguinte temática, respectivamente: (1) a cibercultura e as tecnologias na educação, (2) a formação de professores de línguas na EaD e no curso de licenciatura em Letras Espanhol e Literatura EaD da UFSM-UAB, (3) as autonarrativas docentes e o narrar-se enquanto ação autopoiética (COSTA; PICCININ, 2020), e (4) a auto-trans-formação docente e a autoavaliação do percurso formativo.

Ao longo de cada semana do curso, as professoras-cursistas participantes foram convidadas pelo professor-mediador ${ }^{12}$ a elaborar autonarrativas, das mais variadas formas: interagindo em fórum, produzindo textos escritos em primeira pessoa (em formato livre), respondendo a questionamentos sobre as temáticas do curso ou sobre suas experiências educacionais etc. Reiteramos que a autonarrativa foi escolhida como instrumento central deste estudo por três razões principais, quais sejam: (1) toda narrativa é uma autonarrativa e, como tal, é também um dispositivo metodológico de uma epistemologia complexa, (2) a ação autopoiética de narrar-se potencializa a subjetivação-cognição humana, e (3) o docente, ao narrar-se, não só explicita e complexifica a presença do observador incluído no ato de narrar (COSTA; PICCININ, 2020), como também vai redesenhando a si e suas práticas educacionais (COSTA, 2021).

Apesar de explicado que a autonarrativa poderia ter formas variadas, sem necessariamente ser restrita à escrita-verbal, na maioria dos casos as professoras-cursistas não fizeram uso de áudios, imagens, vídeos etc.

\section{CARTOGRAFANDO NO FLUXO DO VIVER}

11 Elas foram convidadas a participar da pesquisa voluntariamente e receberam informações explicitas do estudo por meio do Termo de Consentimento Livre Esclarecido, atendendo aos requisitos do Comitê de Ética em Pesquisa, via PPGL-UNISC. Número do CAAE: 24205119.6.0000.5343. Também por razões de ética e anonimato, os nomes das professoras-cursistas serão suprimidos, sendo empregada apenas a letra inicial, a exemplo de "professora A", "professora L" e assim por diante.

$12 \mathrm{O}$ primeiro autor deste artigo. 
As autonarrativas das professoras-cursistas, participantes da referida "oficina de $\mathrm{si}^{13 "}$, servem aos propósitos da cartografia complexa em fluxo. Essas autonarrativas ajudam a cartografar uma epistemologia complexa no fluxo do viver, no sentido de serem registros daquilo que, numa lógica complexa, é mapeado e pensado em termos de emergências e padrões. Dentre as emergências e os padrões notados nas autonarrativas semanais produzidas pelas participantes da pesquisa, podemos confirmar a presença mais explícita de dois dos marcadores que estudos recentes (PELLANDA, 2008; CHAGAS, 2019) têm elencado: (1) o acoplamento tecnológico e o (2) processo de autopoiesis. Em função do limite de laudas para registro da pesquisa, apenas para fins de ilustração, apresentaremos de forma breve alguns fragmentos das narrativas referentes a esses dois marcadores.

\subsection{O ACOPLAMENTO-TECNOLÓGICO}

Viver é uma ação efetiva ${ }^{14}$, que implica em invenção de saberes-acontecimentosdevires, e essa invenção "é emergência dos acoplamentos humanos em seus devires consigo mesmos e com o meio de forma dinâmica e criadora" (GUSTSACK; PELLANDA; BOETTCHER, 2017, p. 21). Para explicar esse fenômeno, temos o conceito de "acoplamento estrutural", que remete a um conjunto de mudanças que o meio possibilita na estrutura cognitiva de um organismo, e que esse mesmo organismo possibilita no meio, em uma relação recursiva.

Essa noção de acoplamento estrutural é resgatada pelos pesquisadores do GAIA de leituras que remetem a von Foerster (2003) e Maturana e Varela (2001). Em comum, tais pensadores têm uma vertente epistemológica complexa que possibilita pensar o viver sempre como constante construção de conhecimento-realidade-sujeito, de forma inseparável (COSTA, 2021). "Essa construção é resultado de experiência do sujeito em seu acoplamento com o meio de forma dinâmica e criadora" (PELLANDA; BOETTCHER, 2017, p. 38), e é a esse fenômeno que chamamos "acoplamento estrutural".

O acoplamento estrutural sempre nos transforma e essa transformação se dá anatômica, fisiológica e subjetivamente devido à plasticidade de nosso sistema nervoso e psíquico. A dimensão rede do funcionamento dos seres vivos nos mostra o papel das conexões em seu desenvolvimento. A vida tem como modelo a rede

\footnotetext{
${ }^{13}$ Forma como eventualmente designamos os cursos de formação docente, enfatizando a autonomia do participante no processo, bem como nosso entendimento de que tal "formação" é, com base em Pellanda e Gustsack (2015), uma auto-trans-formação. Ver mais em Costa (2021).

${ }^{14}$ Ou seja, "uma efetividade operacional no domínio de existência do ser vivo" (MATURANA; VARELA, 2001, p. 35).
} 
que está presente não somente no nível relacional com o mundo externo, mas, também, internamente com as redes de conexões orgânicas (GUSTSACK; PELLANDA; BOETTCHER, 2017, p. 38).

Chagas (2019), ao abordar essa noção de acoplamento, aponta que os avanços na produção de tecnologias cada vez mais intuitivas têm proporcionado mudanças significativas nos grupos sociais. Consequentemente, não dá para retroceder esse movimento de um mundo mais conectado, de menos distâncias nos modos de comunicação e, principalmente, de inúmeras alternativas para se (re)pensar a educação (CHAGAS, 2019). Em outras palavras: nossa educação, acompanhando a tendência da cibercultura, caminha rumo às conexões e às interações múltiplas, cada vez mais complexas e rizomáticas, entre humanos-tecnologiasaprendizagens (COSTA, 2021).

Com tudo o que foi registrado até aqui, é possível correlacionar o acoplamento estrutural com a nova cultura de uma sociedade informatizada, que passou por uma inegável mutação antropológica e que, por isso mesmo, mudou as condições de acoplamento estrutural sujeito-meio (PELLANDA; BOETTCHER, 2017).

Temos que nos habituar a pensar a cognição e a realidade a partir do acoplamento estrutural que se dá hoje sobre novos suportes e novos sujeitos. Portanto, esse acoplamento pode se dar com pessoas, coisas, máquinas ou natureza (PELLANDA; BOETTCHER, 2017, p. 51).

Nesse sentido, temos o "acoplamento tecnológico" (ver PELLANDA et al., 2017; PELLANDA; BOETTCHER, 2017; LIMBERGER et al., 2017; CHAGAS, 2019), conceito inspirado pelo acoplamento estrutural. O acoplamento tecnológico, no âmbito educacional (seja ele escolar, universitário, formal ou não formal etc.), pode operar na integração da realidade técnica à cultura social, fundando uma educação mais complexa, inserindo, assim, a tecnologia em suas dimensões social, política e pedagógica (CHAGAS, 2019).

Considerando essa concepção de acoplamento tecnológico, passamos às autonarrativas, que apontaram para as vivências das professoras participantes da pesquisa com relação às tecnologias, principalmente no curso de licenciatura em Letras EaD. Muito possivelmente essa correlação se dá por tal modalidade, a EaD, ser fortemente balizada pelas tecnologias educacionais digitais, e por propiciar nos acadêmicos ruídos e perturbações que complexificam o próprio acoplamento tecnológico (COSTA, 2021). Exemplo disso é a autonarrativa da professora C: 
Percebi no decorrer do curso que é fundamental para um professor manter-se atualizado nas diversas áreas do conhecimento e para isso é inevitável estar em contato com a tecnologia ${ }^{15}$. (professora C)

Para a professora C, então, o "contato com a tecnologia" - uma forma de conceber o acoplamento tecnológico - leva ela à atualização constante, o que parece aludir a uma noção de contínua reinvenção do indivíduo (COSTA, 2021).

Em outros casos, uma maior consciência de si e de seus entendimentos sobre as tecnologias é o que motivou o ingresso no curso de extensão ofertado via projeto interinstitucional (UNISC-UFSM), conforme pode ser visto na autonarrativa a seguir, escrita na primeira semana do curso:

O meu interesse pelo curso vem de acreditar que posso e devo usar melhor os recursos tecnológicos em minhas aulas, mas de entender que não sei bem como fazê-lo. Acredito que o primeiro passo seja discutir e estudar o assunto como fazemos aqui, por isso estou muito feliz em participar desta formação. (professora N)

Essa ideia de um aprimoramento de si, no sentido de buscar participar de cursos e espaços de compartilhamento, diálogo e autorreflexão, sugerem uma percepção de aprendizagem contínua, inacabamento contínuo e auto-trans-formação em devir da professora N. Não só dela, mas das demais participantes que registram em suas narrativas um interesse pelo estabelecimento de diálogos para fins de olhares mais complexos sobre a tecnologia (COSTA, 2021).

Em geral, as autonarrativas indicam que as professoras-cursistas concordam que as tecnologias digitais contemporâneas são muito importantes no fazer educacional atual. "A educação atualmente, não mais é a mesma, sendo imprescindível que a internet e o cyber espaço sejam incorporados em nosso dia-a-dia", segundo palavras da professora J. Uma das ideias mais comumente mapeadas nas narrativas é a de "oportunidade de aprender muito com as tecnologias", como apontou a professora L. Esse parece ser um aspecto mapeado que é potente, pela mediação de um aprender não apenas sobre as tecnologias, mas com elas (COSTA, 2021).

Com nossa cartografia complexa, confirmamos o que já foi apontado por Pellanda et al. (2017): vivenciamos, em muitos casos, a ultrapassagem de uma visão ingênua que delega

\footnotetext{
${ }^{15}$ Este e os demais grifos nos trechos das autonarrativas são de parte dos autores deste artigo, e são empregados para sinalizar aos leitores o motivo para tal excerto ter sido selecionado em nossas pesquisas, para o debate sobre determinados tópicos.
} 
à tecnologia um valor diferente que não o de auxiliar na forma de aprendizagem e interação dos seres humanos. A cartografia complexa serviu, enquanto método, para pensarmos a tecnologia como inseparável da constituição dos seres humanos. Nossa contribuição, nesse sentido, assim como em Pellanda et al. (2017), foi trazermos experiências concretas no processo de utilização das tecnologias e, a partir da reflexão sobre a cartografia vivenciada num espaço online, mostrarmos como, na práxis, pode emergir subjetividade-conhecimento através do uso de tecnologias digitais.

\subsection{O PROCESSO DE AUTOPOIESIS}

Maturana e Varela (2001) nos ensinam que conhecer é viver, bem como viver é conhecer, no sentido de que a cognição-subjetivação está atrelada à atividade de um sujeito escaneando seu ambiente e dando a ele respostas efetivas engendradas por ele mesmo. Essas respostas efetivadas - esse complexo ato de interação-acoplamento com o meio - nos levam ao processo constante de auto-trans-formação (COSTA, 2021). Assim, no coração da Biologia da Cognição está o conceito organizador de autopoiesis, que explica o funcionamento dos seres vivos como máquinas que se produzem a si mesmos ao operar (PELLANDA; BOETTCHER; PINTO, 2017). A referida expressão é de origem grega e significa: auto - por si e poiése - produção, "o que implica pensar que o viver sucede autoprodutivamente nos organismos vivos" (PELLANDA et al., 2017, p. 140).

A autopoiesis, enquanto conceito criado por Maturana e Varela (2001) para dar conta do fenômeno do viver, serve para a finalidade de explicar os fenômenos moleculares e o operar em organismos moleculares. Os humanos vivem essa mesma dinâmica molecular (PELLANDA et al., 2017).

Concebendo o Paradigma da Complexidade como um conjunto de teorias que se interconectam na tessitura de uma forma holística de pensar e viver, temos na Teoria da Autopoiesis subsídios para metaforizar a própria constituição de um "eu" na ação de pesquisar. Parte daí, inclusive, nossa interpretação do narrar - que é sempre autonarrar como uma prática autopoiética (o narrador se autoconstitui ao narrar-se). No caso da cartografia complexa, estamos nos referindo, com a noção de autopoiesis, à sensação da autoprodução oriunda da circularidade resultante da utilização do instrumento de pesquisa para pesquisar o próprio instrumento de pesquisa (MATURANA; VARELA, 2001). 
As reflexões sobre o processo de autoprodução estiveram presentes ao longo de todo o curso online, mas principalmente nas autonarrativas finais, da última semana do curso, quando as professoras-cursistas foram provocadas a avaliar a ação extensionista e seu próprio percurso formativo em um curso de Letras na modalidade EaD. Dessa provocação emergem fragmentos autonarrativos como este:

Depois de rever o material do curso e refletir para escrever essa última narrativa sobre o que aprendi e o que mudou na minha forma de pensar sobre os temas abordados nos estudos, vejo que somos seres em constante construção. (professora C)

Subjacente ao fragmento da narrativa da professora há uma correlação entre aprender e mudar, ou se auto-trans-formar. Esse processo parece ser contínuo no sentido de tal construção de si ser constante (COSTA, 2021).

A professora A, por sua vez, já havia avaliado sua própria aprendizagem antes da proposta de narrativa da semana final do curso:

Antes mesmo de ver a proposta do trabalho final, já tinha pensando em como esse curso me fez refletir, através das autonarrativas e da escrita. Eu começava a escrever e mil coisas surgiam na minha cabeça sobre os assuntos. Finalizo minha narrativa afirmando que este curso ajudou e muito na minha formação, me ajudando a refletir sobre os temas abordados. (professora A)

Assim como a professora A, a professora Z também considerou positiva a oportunidade de produzir autonarrativas, por ser esta uma técnica de si, uma técnica de autoconhecimento:

[...] tive a oportunidade de me auto conhecer e fazer poesia com meu aprendizado através de narrativas para mim mesma. (professora Z)

Em alguns casos, conforme o trecho da autonarrativa (da professora G) a seguir, podemos notar, ainda, a correlação entre o processo de autopoiesis e o acoplamento tecnológico, na medida em que a tecnologia perturba e dispara mudanças e transformações no indivíduo. Nem sempre tal processo é fácil, pois, como a própria professora G aponta, há "riscos" quanto ao uso de novas tecnologias, mas estas reverberam novas experiências, o que afeta a autoconstituição em devir do indivíduo: 
Todas essas experiências, presenciais e virtuais, colaboraram para $a$ construção da pessoa que sou e serei. Por isso, sou uma entusiasta das novas tecnologias, mesmo sabendo que há "riscos", mas penso que riscos há em todo lugar. (professora $\mathrm{G}$ )

Assim como vem sendo demonstrado nos estudos do GAIA, o processo autopoiético se dá pelo caos, pelo ruído (CHAGAS, 2019; GUSTSACK; PELLANDA; BOETTCHER, 2017), e pela desestabilização-reorganização recursiva. Isso se mostra no repensar de si, que configura a aprendizagem, conforme pode ser lido na autonarrativa da professora A: "Como disse acima, eu nem tinha me dado conta que era possível formar grupos no Facebook para estudar". Ou seja, tomar consciência de algo pode significar, em grande medida, uma aprendizagem sobre algo até então desconhecido e, logo, uma mudança (transformação) do indivíduo (COSTA, 2021).

\section{CONSIDERAÇÕES FINAIS}

Com o respaldado da literatura da área, conseguimos elencar aspectos que ajudam na proposição do conceito de "cartografia complexa": (1) o observador incluído, (2) o processo em sintonia com o próprio processo, (3) as narrativas (autonarrativas) e (4) os marcadores. Também conseguimos efetivar a implementação desse método cartográfico em uma experiência de curso online de formação docente para professoras graduadas e graduandas de um curso de licenciatura em Letras EaD. No mencionado curso, um olhar sensível sobre as emergências registradas nas autonarrativas mostrou-se pertinente.

Embora as autonarrativas produzidas no curso de formação docente tenham se limitado quase que exclusivamente ao registro verbal-escrito, reiteramos que outros meiosmodos de narrar-se podem servir ao cartografar complexo. Imagens, vídeos, diários de bordo, conversas informais, poesia, questionamentos e registros de todas as ordens podem compor essa cartografia complexa. E, pela junção de todos esses formatos possíveis interpretados à luz do princípio hologramático da Complexidade, que aponta para a recursividade (ou fractalidade) da relação todo-partes -, o indivíduo pode ir se narrando e, assim, redesenhando seu viver. Nesse sentido, concordamos com o apontamento de Pellanda et al. (2017), de que, num relatório final, o que aparece é uma verdadeira cartografia de emergências que adquirem sentido à luz dos marcadores, como o processo autopoiético e o acoplamento tecnológico, por exemplo. Ainda que outros formatos de 
narrativa não tenham sido amplamente empregados pelas professoras-cursistas, o registro verbal-escrito já serve ao propósito da cartografia complexa, por ser uma parte inscrita no todo, ao passo que o todo está inscrito na parte (COSTA, 2021).

A partir deste trabalho mostrou-se possível confirmar que, no método cartográfico, o pesquisador (cartógrafo) também é ator na realidade pesquisada e está implicado no observar, sendo seu papel exatamente este: observar onde o fluxo o leva, se adaptando às realidades que the são expostas, e buscando produzir mapas que evidenciem essas experiências vivenciadas junto aos demais participantes da pesquisa (LIMBERG et al., 2017).

Com este primeiro estudo sobre o método em questão, podemos interpretar que a cartografia complexa serve ao propósito de mapear marcadores como o acoplamento tecnológico e o processo de autopoiesis do humano, em uma lógica complexa. Tanto o ensino de línguas mediado por tecnologias, no qual está diretamente imbricado o acoplamento-tecnológico, quanto o processo de formação de professores de línguas, que pode ser pensado à luz da autopoiesis e da Biologia da Cognição, são interesses centrais da LA, o que é indicativo de uma sintonia entre a área e o método da cartografia complexa.

Este artigo, evidentemente, não esgota o tema, e a cartografia complexa ainda demandará uma série de pesquisas, sobretudo em relação a outros tópicos da LA, para além das tecnologias e do processo de formação docente. De antemão, todavia, já podemos avaliar positiva a adoção do método cartográfico no viés do Pensamento Complexo, não apenas pela experiência de avaliação do curso de formação docente com professores de línguas da EaD, mas pelo papel da linguagem como prática social, tão caro à LA. Subjacente ao narrar-se e, por conseguinte, ao cartografar, está uma noção complexa de língua/linguagem, que encontra eco nos apontamentos da Biologia da Cognição sobre o operar do observador incluído, que se dá na linguagem. À luz da Biologia da Cognição, a linguagem e o operar do observador não requerem nem referenciam uma realidade externa: o mundo das descrições e explicações do observador é um mundo de modos de convivência gerador de objetos perceptivos, no qual o observador surge como um deles ao surgir a linguagem, segundo Maturana (1997). Futuras pesquisas, então, podem ater-se à questão da linguagem na cartografia complexa mais pontualmente. 


\section{REFERÊNCIAS}

ARAGÃO, R. Cognição, emoção e reflexão na sala de aula: por uma abordagem sistêmica do ensino/aprendizagem de inglês. Revista Brasileira de Linguística Aplicada, vol. 5, no 2, 2005.

BARROS, L. P.; KASTRUP, V. Cartografar é acompanhar processos. In: PASSOS, E.; KASTRUP, V.; ESCÓSSIA, L. (Org.) Pistas do método da cartografia: pesquisa-intervenção e produção de subjetividade. Porto Alegre: Sulina, 2009, p. 52-75.

BATESON, G.; BATESON, M.C. El Temor de los Ángeles. Epistemología de lo Sagrado. Barcelona: Gedisa, 2000.

CHAGAS, M.F.L. \#EntreNÓSnaRede: Ontoepistemogênese de Educadores na Interação com Tecnologias Digitais. Texto de qualificação de Tese de Doutorado em Educação. UNISC: Santa Cruz do Sul. 2019.

COSTA, A.R. Contribuições para uma cartografia complexa da ontoepistemogênese: autonarrativas e formação docente na Educação a Distância. Tese de Doutorado em Letras. UNISC: Santa Cruz do Sul. 2021.

COSTA, A.R. Sistemas Adaptativos Complexos e Linguística Aplicada: organizando a literatura da área. Domínios de Lingu@gem, v. 14, 2020, p. 311-339.

COSTA, A.R.; FIALHO, V.R.; BEVILÁQUA, A.F.; LEFFA, V.J. Um olhar complexo sobre o Feedback e a formação de professores a distância. Revista Polifonia: Estudos da Linguagem, v. 26,2019, p. $57-80$

COSTA, A.R.; FIALHO, V.R.; BEVILÁQUA, A.F.; OLIVEIRA, E. 10 anos de Jornada de Elaboração de Materiais, Tecnologia e Aprendizagem de Línguas: Estado da Arte. In: LEFFA; V.J.; FIALHO, V.R.; BEVILÁQUA, A.F.; COSTA, A.R. (Org.) Tecnologias e ensino de línguas: uma década de pesquisa em Linguística Aplicada. Santa Cruz do Sul: EDUNISC, 2020, p. 19-43.

COSTA, A.R.; PICCININ, F. Memoriais autobiográficos no viés da Complexidade: um conceito para a formação docente. Revista Gatilho, v. 18, 2020, p. 231-252,

DELEUZE, G. Empirismo e subjetividade. Tradução: Luiz Orlandi. Rio de Janeiro: Editora 34, 2001.

DELEUZE, G.; GUATTARI, F. Mil Platôs: capitalismo e esquizofrenia, vol. 1. Rio de Janeiro: Editora 34, 1995.

ESCÓSSIA, L.; TEDESCO, S. O coletivo de forças como plano da experiência cartográfica. In: PASSOS, E.; KASTRUP, V.; ESCÓSSIA, L. (Org.) Pistas do método da cartografia: pesquisaintervenção e produção de subjetividade. Porto Alegre: Sulina, 2009, p. 92-108.

GAI, E.T.P. Narrativas e conhecimento. Desenredo, vol. 5, no 2, 2009, p. 137-144.

GONÇALVES, O. Psicoterapia cognitiva narrativa: manual de terapia breve. São Paulo: Editorial PSY, 1998. 
GUATTARI, F.; ROLNIK, S. Micropolítica: Cartografias do Desejo. 4a ed. Petrópolis: Vozes, 1996.

GUSTSACK, F.; PELLANDA, N.M.C.; BOETTCHER, D.M. Contribuições para uma Epistemologia da Complexidade. In: PELLANDA, N.M.C.; BOETTCHER, D.M.; PINTO, M.M. (Org.) Viver/Conhecer na perspectiva da Complexidade: Experiências de pesquisa. Santa Cruz do Sul: EDUNISC, 2017, p. 15-26.

KASTRUP, V.; BARROS, R.B. Movimentos-funções do dispositivo na prática da cartografia. In: PASSOS, E.; KASTRUP, V.; ESCÓSSIA, L. (Org.) Pistas do método da cartografia: pesquisaintervenção e produção de subjetividade. Porto Alegre: Sulina, 2009, p. 92-108.

LARSEN-FREEMAN, D. Chaos/complexity science and second language acquisition. Applied Linguistics, v. 18, $n^{\circ} 2,1997$, p. 141-165.

LEFFA, V.J. A Linguística Aplicada e seu compromisso com a sociedade. In: VI Congresso Brasileiro de Linguística Aplica (CBLA). Anais... 2001. Belo Horizonte: Universidade Federal de Minas Gerais. 2001.

LIMBERGER, L.S.; PINTO, M.M.; MÜLLER, C.A.; TURCATTO, P.C. O aprender em jogo: videogames e o Paradigma da Complexidade. In: PELLANDA, N.M.C.; BOETTCHER, D.M.; PINTO, M.M. (Org.) Viver/Conhecer na perspectiva da Complexidade: Experiências de pesquisa. Santa Cruz do Sul: EDUNISC, 2017, p. 185-203.

MATURANA, H. A ontologia da realidade. Belo Horizonte: UFMG, 1997.

MATURANA, H.; VARELA, F. A Árvore do Conhecimento: as bases biológicas da compreensão humana. São Paulo: Palas Athena, 2001.

MOITA-LOPES, L.P. (Org.) Por uma Linguística Aplicada Indisciplinar. São Paulo: Parábola, 2006.

MORIN, E. O Método 1: a Natureza da Natureza. Tradução: Maria Gabriela de Bragança. 2a ed. Portugal: Publicações Europa-América. 1977.

OLIVEIRA, C.C. Análise e desenvolvimento de conceitos base no GAIA: aprendizagemeducação; Complexidade; padrão; narrativa; metáfora. In: PELLANDA, N.M.C.; BOETTCHER, D.M.; PINTO, M.M. (Org.) Viver/Conhecer na perspectiva da Complexidade: Experiências de pesquisa. Santa Cruz do Sul: EDUNISC, 2017, p. 88-103.

PAIVA, V.L.M.O. Manual de Pesquisa em Estudos Linguísticos. São Paulo: Parábola, 2019.

PASSOS, E.; BARROS, R.B. A cartografia como método de pesquisa-intervenção. In: PASSOS, E.; KASTRUP, V.; ESCÓSSIA, L. (Org.) Pistas do método da cartografia: pesquisa-intervenção e produção de subjetividade. Porto Alegre: Sulina, 2009, p. 17-31. 
PATY, M. A noção de determinismo na física e seus limites. Scientiae Studia, vol. 2, n. 4, 2004.

PELLANDA, N.M.C. Sofrimento escolar como impedimento da construção de conhecimento/ subjetividade. Revista Educação \& Sociedade, vol. 29, 2008, p. 1069-1088.

PELLANDA, N.M.C.; BOETTCHER, D.M. O esgotamento do paradigma clássico e a emergência da Complexidade. In: PELLANDA, N.M.C.; BOETTCHER, D.M.; PINTO, M.M. (Org.) Viver/Conhecer na perspectiva da Complexidade: Experiências de pesquisa. Santa Cruz do Sul: EDUNISC, 2017, p. 27-75.

PELLANDA, N.M.C.; BOETTCHER, D.M.; PINTO, M.M. (Org.) Viver/Conhecer na perspectiva da Complexidade: Experiências de pesquisa. Santa Cruz do Sul: EDUNISC, 2017, p. 129-154.

PELLANDA, N.M.C.; GUSTSACK, F. Formação de Educadores na perspectiva da Complexidade: autonarrativas e autoconstituição. Educação e Filosofia (Online), v. 1, 2015, p. 35-45.

PELLANDA, N.M.C.; KELLER, D.S.; BENEDUZI, P.K.S.; VEIGA, L.F.; MEINHARDT, Y.; BORSTMANN, R.S.; SILVA, L.E.C.; LIMA, L.M.P. Na ponta dos dedos: o iPad como instrumento complexo de cognição/subjetivação. In: PELLANDA, N.M.C.; BOETTCHER, D.M.; PINTO, M.M. (Org.) Viver/Conhecer na perspectiva da Complexidade: Experiências de pesquisa. Santa Cruz do Sul: EDUNISC, 2017, p. 129-154.

PIMENTA, O. Como devemos viver? Duas formulações do tema a partir do Livro I da "República". Kriterion: Revista de Filosofia, vol. 60, n. 144, 2019, p. 651-669.

ROLNIK, S. Cartografia sentimental: transformações contemporâneas do desejo. São Paulo: Estação Liberdade, 1989.

ROLNIK, S. Uma insólita viagem à subjetividade: fronteiras com a ética e a cultura. In: LINS, D. (Org.) Cultura e subjetividade: saberes nômades. Campinas: Papirus, 1997, p. 25-34.

Recebido em 21 de junho de 2020.

Aprovado em 07 de janeiro de 2021.

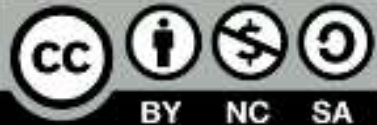

